Research Article

\title{
Comparative Analysis of Thermomechanical Properties and Thermal Damage Constitutive Models of Three Soft Sedimentary Rocks
}

\author{
Wenhua Zha $\mathbb{D}^{1,}{ }^{1,2}$ Weixing Shao, ${ }^{1}$ Suqin Yao, ${ }^{1}$ Qiang Chen, ${ }^{1}$ and Denghong Chen ${ }^{2}$ \\ ${ }^{1}$ School of Civil and Architectural Engineering, East China University of Technology, Nanchang, Jiangxi 330013, China \\ ${ }^{2}$ School of Energy and Security, Anhui University of Science and Technology, Huainan, Anhui 232001, China \\ Correspondence should be addressed to Wenhua Zha; whzha@126.com
}

Received 14 September 2020; Revised 18 October 2020; Accepted 27 November 2020; Published 18 December 2020

Academic Editor: Yu-Wei Chen

Copyright (C) 2020 Wenhua Zha et al. This is an open access article distributed under the Creative Commons Attribution License, which permits unrestricted use, distribution, and reproduction in any medium, provided the original work is properly cited.

In order to study the difference in thermomechanical properties of soft sedimentary rocks of different coal measures, three types of soft sedimentary rocks, sandstone, sandy mudstone, and mudstone, which are common in deep mines, are tested using the RMT150B rock mechanics test system and GD-65/150. Uniaxial compression experiments were conducted on three kinds of soft rockcement mixed specimens at $25^{\circ} \mathrm{C} \sim 55^{\circ} \mathrm{C}$ multistage temperature in an environmental chamber. The difference of important parameters such as stress-strain curve, peak stress, and elastic modulus was analyzed and compared. The results show that (i) in the test temperature range, the stress-strain curves of the three types of soft rocks at different temperatures are roughly divided into four stages: compaction, elasticity, yield, and failure. The proportion of deformation in the compaction stage to the total deformation decreases gradually with the increase of temperature. (ii) When the temperature is lower than $40^{\circ} \mathrm{C}$, the yield stage is shorter, and the peak stress and elastic modulus of the three types of soft rocks decrease significantly with the increase of temperature. (iii) Above $40^{\circ} \mathrm{C}$, the decreasing trend of peak stress and elastic modulus curve decreases, and the yield stage becomes more and more obvious. The decreasing rate of elastic modulus of sandstone is $0.041 \mathrm{GPa} /{ }^{\circ} \mathrm{C}$; the decreasing rate of peak stress is $0.193 \mathrm{MPa} /{ }^{\circ} \mathrm{C}$, the decreasing rate of sandy mudstone is $0.022 \mathrm{GPa} /{ }^{\circ} \mathrm{C}$ and $0.124 \mathrm{MPa} /{ }^{\circ} \mathrm{C}$, and the decreasing rate of mudstone is $0.020 \mathrm{GPa} /{ }^{\circ} \mathrm{C}$ and $0.051 \mathrm{MPa} /{ }^{\circ} \mathrm{C}$. (iv) The rationality of the established thermal damage constitutive model of sedimentary soft rock was verified.

\section{Introduction}

With the rapid development of economy, society, and mining technology, the huge resource consumption has gradually depleted the shallow earth's resources. In the future, global mining will surely enter the deep stage. At present, there are many deep mining wells at home and abroad, such as the Champinliv mine (mining depth $>3260 \mathrm{~m}$ ), Russia Liwoluog Iron Mine (there are 8 mines with a mining depth of $1570 \mathrm{~m}$ ), Shenyang Caitun Mine (mining depth of $1197 \mathrm{~m}$ ), and China Kailuan Zhaogezhuang Mine (mining depth of $1159 \mathrm{~m}$ The average mining depth of large- and medium-sized mines in China is more than $500 \mathrm{~m}$ and extends downward at a rate of $8-12 \mathrm{~m} /$ year. Among them, the eastern mining area has entered the deep mining stage at a rate of $10-25 \mathrm{~m} /$ year [1]. The coal mine will enter the deep mining stage with a mining depth of $1000 \sim 1500 \mathrm{~m}$ [2]. After the mining enters the deep part, the original rock temperature will continue to rise [3]. With the increase of the temperature influencing factor, the cumulative deformation of the rock mass also increases [4], forming the problem of mine heat damage, so the high temperature problem of deep underground mines has become a restriction on the development of deep mine resources, the construction of high-level radioactive nuclear waste repositories, and the development and utilization of deep underground spaces $[5,6]$. Therefore, the mechanics of the surrounding rock of the mine at high temperature has become one of the main directions of rock mechanics research [7]. 
Literature retrieval and analysis show that the research on safe production in deep mines has achieved certain results, mainly in two aspects: the stress of the surrounding rock in the high temperature $\left(>100^{\circ} \mathrm{C}\right)$ range [8] and the mechanical properties of hard rock masses of the study.

\subsection{Research on the Stress of the Surrounding Rock in the High} Temperature $\left(>100^{\circ} \mathrm{C}\right)$ Range. Yin et al. [7, 9] studied the failure mode, peak strength, and peak strain of sandstone at five temperatures, i.e., $25^{\circ} \mathrm{C}, 200^{\circ} \mathrm{C}, 400^{\circ} \mathrm{C}, 600^{\circ} \mathrm{C}$, and $800^{\circ} \mathrm{C}$. Zhang et al. [10] analyzed the dynamic stress, strain, strain rate, fractal dimension, failure mode, and damage level of sandstone under hot treatment of temperature range between $-15^{\circ} \mathrm{C}$ and $800^{\circ} \mathrm{C}$. Zhang et al. [11] studied the mechanical properties and seepage characteristics of red sandstone under different high temperature environments; $\mathrm{Wu}$ et al. [12] carried out experimental research on the mechanical properties of Xuzhou marble at normal temperature to $800^{\circ} \mathrm{C}$ and analyzed in detail the changes of the peak stress, peak strain, elastic modulus, and the whole stress-strain curve of the marble. Chen and Zhang [13] conducted experimental research on the physical and mechanical properties of limestone from 5 different areas at room temperature and after heat treatment at different temperatures of $100^{\circ} \mathrm{C} \sim 800^{\circ} \mathrm{C}$ and discussed the volume density, porosity, longitudinal wave velocity, elastic modulus, and tensile and compressive strength changes of limestone after high temperature; Qi et al. [14] studied the influence of high temperatures $\left(25^{\circ} \mathrm{C}, 200^{\circ} \mathrm{C}, 400^{\circ} \mathrm{C}\right.$, and $600^{\circ} \mathrm{C}$ ) on dynamic mechanical properties and energy evolution characteristics of limestone samples; Wang et al. [15] compared the dynamic mechanical properties of layered salt rock and mudstone interlayers and established a dynamic strength formula with a better fitting result; Yuan et al. [16] studied the coupling effect of water temperature and dry-wet cycle on the dynamic mechanical properties of sandstone; Zhang and Yuan [17] performed a study on sandstone after repeated cooling and heating cycles (H-C). The split-Hopkinson pressure bar (SHPB) test was carried out to investigate the physical and mechanical properties and damage and fracture characteristics of sandstone after the H-C cycle; Li et al. [18] established a constitutive model of coal and rock damage based on the temperature effect considering thermal damage $D_{T}$ and damage correction coefficient $q$; Chen et al. [19] studied the coupling effects of freeze-thaw temperature and dynamic load on the dynamic mechanical properties and fracture mechanism of saturated yellow sandstone.

\subsection{Research on Mechanical Properties of Hard Rock Mass.} Liu et al. [20] studied the longitudinal wave velocity, compressive strength, failure mode, and damage characteristics with temperature of marble after hot treatment at different temperatures $\left(25 \sim 1000^{\circ} \mathrm{C}\right)$ through uniaxial compression tests; in addition, $\mathrm{Wu}$ et al. [21] conducted experimental studies on the physical and mechanical properties of Jiaozuo limestone at room temperature and different temperatures from $100^{\circ} \mathrm{C}$ to $800^{\circ} \mathrm{C}$; in addition,
Torabi-Kaveh et al. etc. [22] used ultrasonic pulse, mercury penetration, polarized light, fluorescence optical microscopy, and microcomputer tomography to evaluate the changes in rock microstructure after thermal shock; Ghobadi and Badazadeh [23] studied the effects of freezing and thawing, thermal shock, and salt crystallization on the physical and mechanical properties of Persepolis stone; Kumari et al. [24] studied temperature influence on the mechanical behavior of rock specimens under triaxial conditions; Wang et al. [25] studied the effects of temperature, confining pressure, and preexisting cracks on the creep characteristics of rock masses. Through uniaxial creep experiments, it is found that the initiation and propagation of microcracks are most obvious at $60^{\circ} \mathrm{C}$ and least obvious at 20 and $50^{\circ} \mathrm{C}$. Uniaxial creep has a greater influence on the steady-state strain rate.

It can be concluded that the above research studies focus on the mechanical properties of brittle, dense, homogeneous, and isotropic rock mass (such as marble, sandstone, and limestone.) under ultrahigh temperature $\left(>100^{\circ} \mathrm{C}\right)$. Although these studies provide a basis for the safety problems caused by the high-speed development of underground space engineering, there is a lack of research on the mechanical properties of coal measure sedimentary soft rocks such as sandstone, mudstone, and sandy mudstone, which are commonly found in mine lithology and affected by mine high temperature. According to the real kilometerdeep mine roadway temperature gradient or ground temperature gradient $\left(30 \sim 50^{\circ} \mathrm{C} / \mathrm{km}\right)[11]$, the mechanical properties of the surrounding rock of the mine are studied within the temperature range of $25^{\circ} \mathrm{C} \sim 55^{\circ} \mathrm{C}$, which is more in line with the actual situation in the underground mine and has more engineering significance. Therefore, it is necessary to study and compare the thermomechanical characteristics of these three lithological rocks within the range of $25^{\circ} \mathrm{C} \sim 55^{\circ} \mathrm{C}$, in order to provide a theoretical basis for the analysis of the surrounding rock deformation mechanism of the roadway under the high-temperature environment of deep wells. In view of this, based on the research results of Zha et al. [26, 27], this paper carried out a contrastive analysis of uniaxial mechanical properties of sandstone, sandy mudstone, and mudstone at the temperature of $25 \sim 55^{\circ} \mathrm{C}$ and constructed a constitutive model of thermal damage of sedimentary soft rock.

\section{Test Process}

2.1. Test Scheme and Method. The RMT-B150 rock mechanics test system and GD-65/150 high- and low-temperature environment chamber were used in this experiment. The mechanical properties of the remolded samples of the three types of original rocks were studied under uniaxial compression tests at temperatures of $25^{\circ} \mathrm{C}$, $30^{\circ} \mathrm{C}, 35^{\circ} \mathrm{C}, 40^{\circ} \mathrm{C}, 45^{\circ} \mathrm{C}, 50^{\circ} \mathrm{C}$, and $55^{\circ} \mathrm{C}$. Three displacement sensors (two lateral displacement sensors and one longitudinal displacement sensor) were installed to monitor the strain of the specimens, as shown in Figure 1. At each temperature level, three rock samples were tested. After the test, the average value of the test results was obtained and 


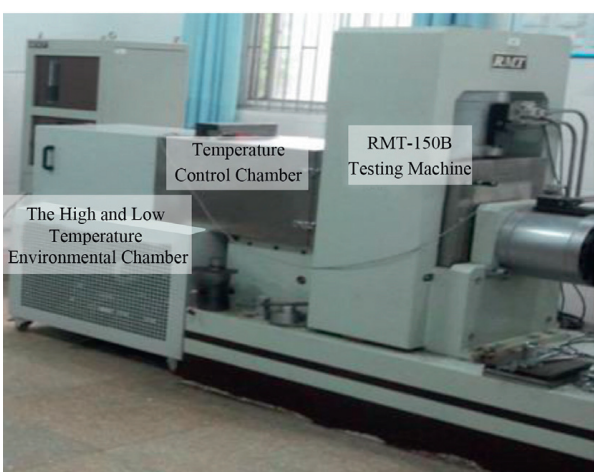

(a)

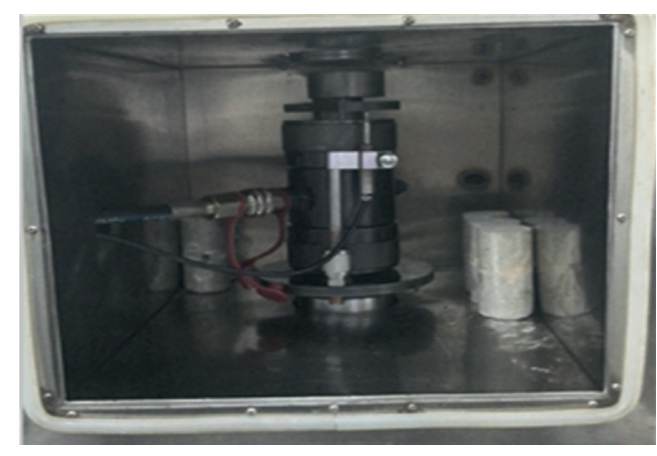

(b)

Figure 1: Test devices. (a) Assembled environmental chamber and RMT-150B testing machine. (b) Displacement sensor.

analyzed, and the corresponding stress-strain curve was drawn. To ensure that the sample is heated uniformly and consistent with the temperature in the box, the sample is heated to a predetermined temperature and then kept at a constant temperature for 2 hours before the uniaxial compression test. After the temperature reaches a predetermined time, a uniaxial compression test is carried out in an environmental chamber until the specimen fails. Taking into account if the heating rate is too fast, the mechanical properties of the rock will be affected, the sample is heated at a heating rate of $1^{\circ} \mathrm{C} /(2 \mathrm{~min})$ in the preparation stage.

2.2. Preparation of Test Piece. The original rocks used in this experiment were taken from the sandstone of the Kouzidong Mine in Anhui Province, the sandy mudstone of the Zhangbei Mine, and the mudstone of the Zhujixi Mine. In order to eliminate the influence of errors caused by different rock masses, environmental factors, and different structural components in the test results and to accurately determine the influence of temperature on the mechanical properties of various soft rocks, the specimens used in this paper are remolded rock specimens with different cement mortar mix ratios based on the uniaxial compressive strength of the original rock. By changing the mix ratio, remolded samples can produce a stress-strain curve similar to the original rock. The result of the mix ratio test piece is shown in Figure 2.

\section{Analysis of Test Results}

3.1. Mechanical Properties of the Same Kind of Soft Rock at Different Temperatures. The stress-strain curves of the three kinds of soft rocks at $25^{\circ} \mathrm{C}, 30^{\circ} \mathrm{C}, 35^{\circ} \mathrm{C}, 40^{\circ} \mathrm{C}, 45^{\circ} \mathrm{C}, 50^{\circ} \mathrm{C}$, and $55^{\circ} \mathrm{C}$ are shown in Figure 3 .

It can be seen from Figure 3 that the mechanical properties of the three soft rocks exhibit the following features:

(i) The full stress-strain curve is roughly divided into four stages: compaction, elasticity, yield, and failure.

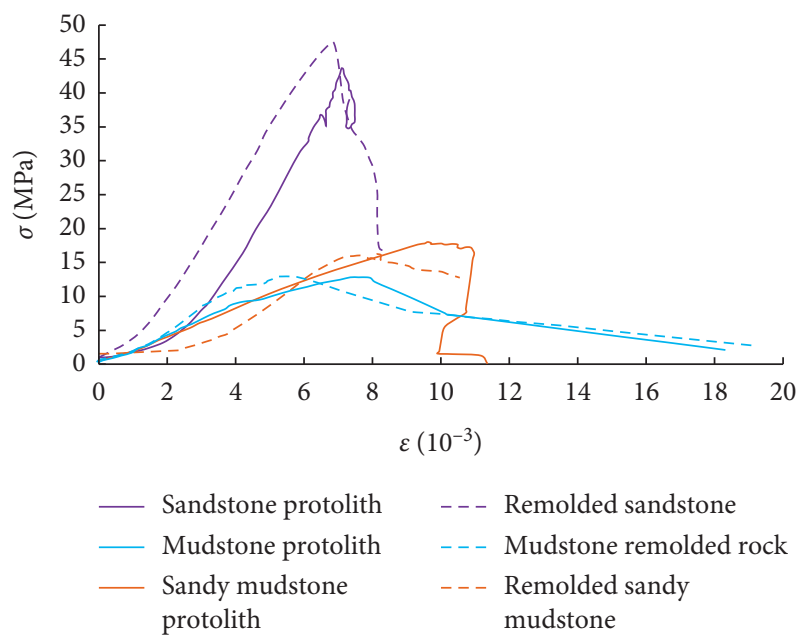

Figure 2: Comparison of mechanical properties of different protorock and remolded rock specimens.

(ii) The initial stage of the compaction stage of the three types of soft rocks gradually moved up with the increase of temperature, that is, the proportion of deformation in the compaction stage to the total deformation gradually decreased. Among them, the deformation of sandstone decreased from $25 \%$ to $20 \%$; deformation of sandy mudstone decreased from $20 \%$ to $12.5 \%$ and deformation of mudstone decreased from $15 \%$ to $14.5 \%$.

(iii) The stresses of the three types of soft rock samples show a decreasing trend. The curves in the elastic phase basically change linearly, and the slope of the curve means that the average elastic modulus of the rock gradually decreases.

(iv) When the temperature is lower than $40^{\circ} \mathrm{C}$, the yield stage of the three types of soft rocks is shorter. The yield stage becomes more and more obvious when the temperature is higher than $40^{\circ} \mathrm{C}$. After the sandstone reaches the failure stage, the rate of stress decline gradually increases and brittle failure occurs, while the stress of 


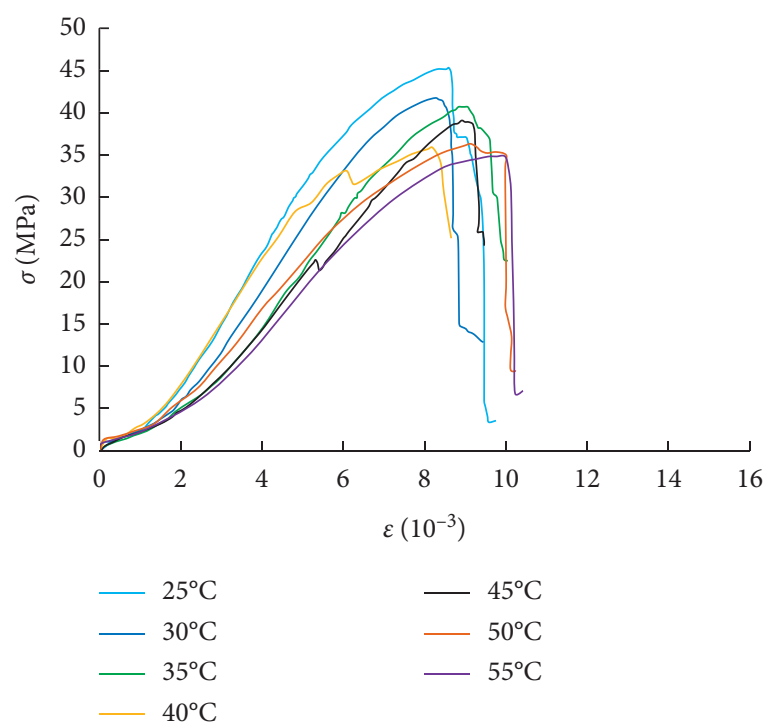

(a)

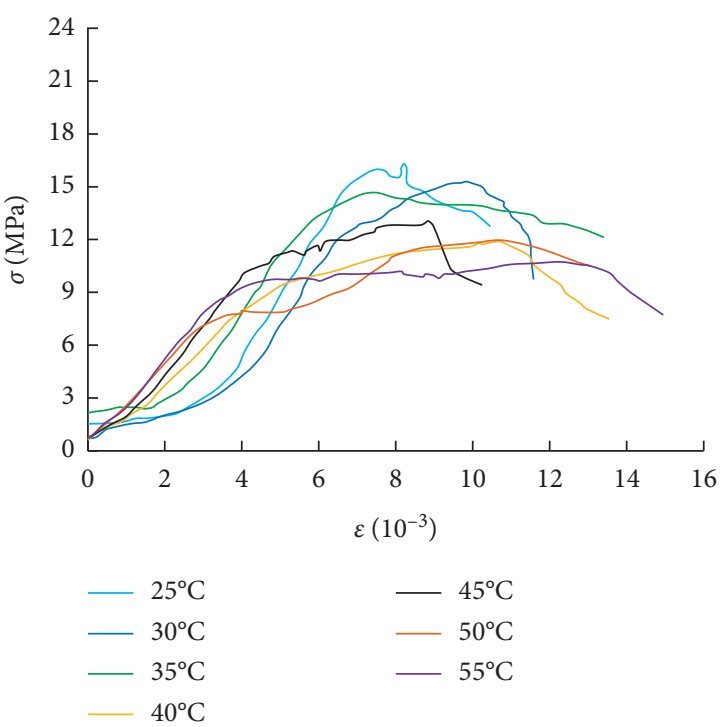

(b)

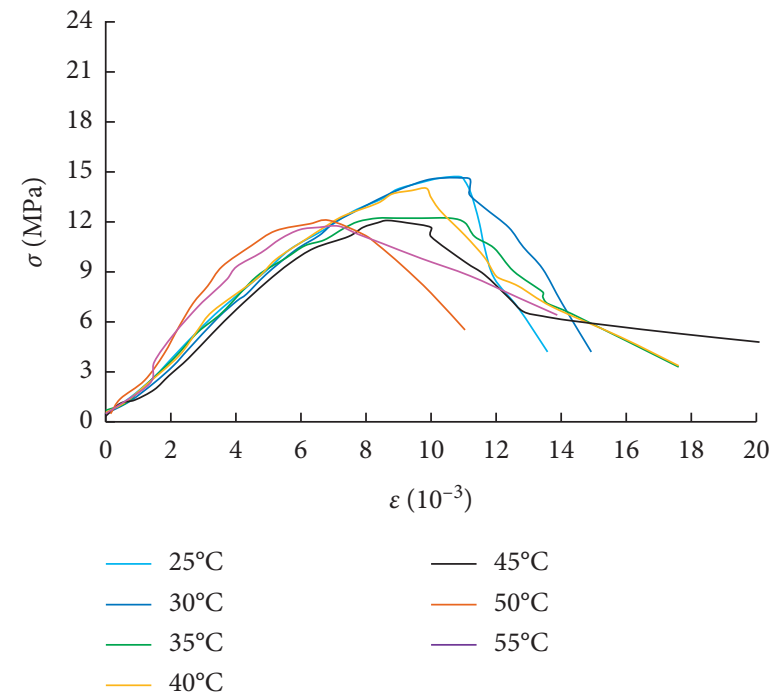

(c)

Figure 3: Stress-strain curves of three types of soft rocks at different temperatures. (a) Sandstone. (b) Sandy mudstone. (c) Mudstone.

mudstone and sandy mudstone will increase before reaching the ultimate strength, plastic failure will occur, and there will be higher residual strength.

\subsection{The Stress-Strain Relationship of Different Rock Masses at} the Same Temperature. The stress-strain relationship of different rock masses at the same temperature is shown in Figure 4.

It can be seen from Figure 4 that

(i) Before the temperature reaches $40^{\circ} \mathrm{C}$, the stress-strain curve of the three types of soft rock specimens is similar. As the temperature increases, the peak stress decreases. In addition, the elastic phase becomes smaller and shifts to the left. The difference is as follows: the sandstone has the largest peak stress and exhibits brittle failure without yield stage; sandy mudstone and mudstone peaks do not show much difference, and both exhibit plastic failure. The yield stage is obvious, and there is a large residual stress.

(ii) When the temperature rises to $40^{\circ} \mathrm{C}$, sandstone has a short yield stage, but still exhibits brittle failure. The yield stage of sandy mudstone and mudstone is more obvious and gentle, and the residual stress gradually increases.

(iii) The main reason for the differences is as follows: the structure of sandstone is granular, which is affected by temperature and pressure. The deformation mainly comes from slip between particles, which reduces cohesion and breaks the structure; the structure of mudstone and sandy mudstone is shale or flake-like layer. Therefore, after being affected by 

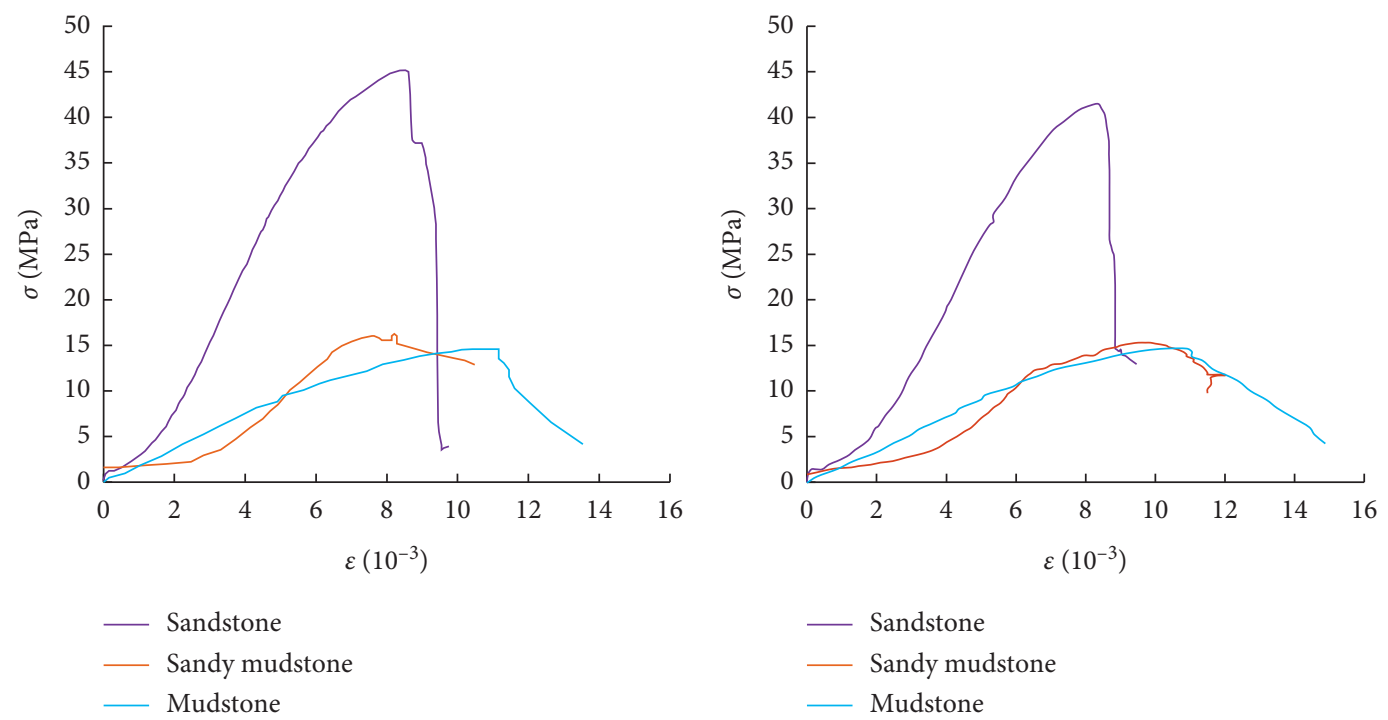

(a)
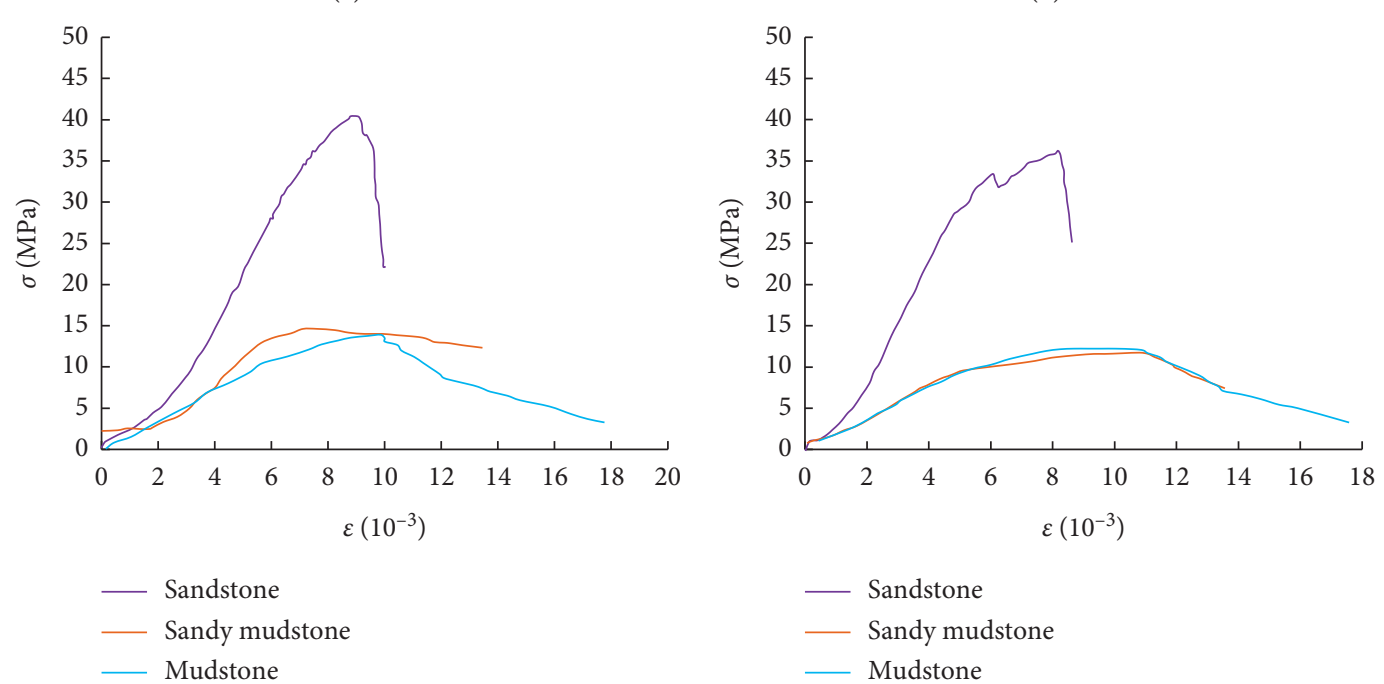

(c)

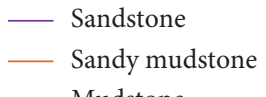

_ Mudstone

(d)
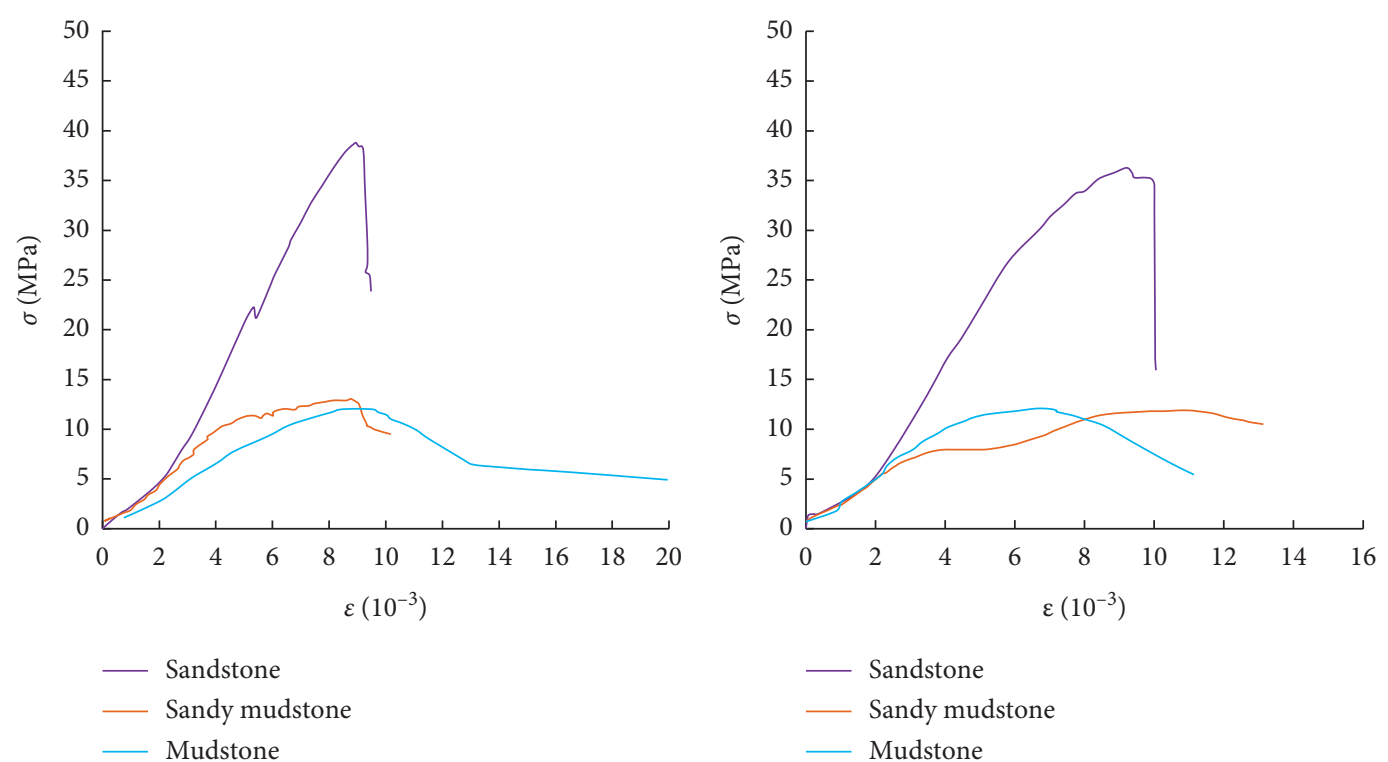

(e)

Figure 4: Continued. 


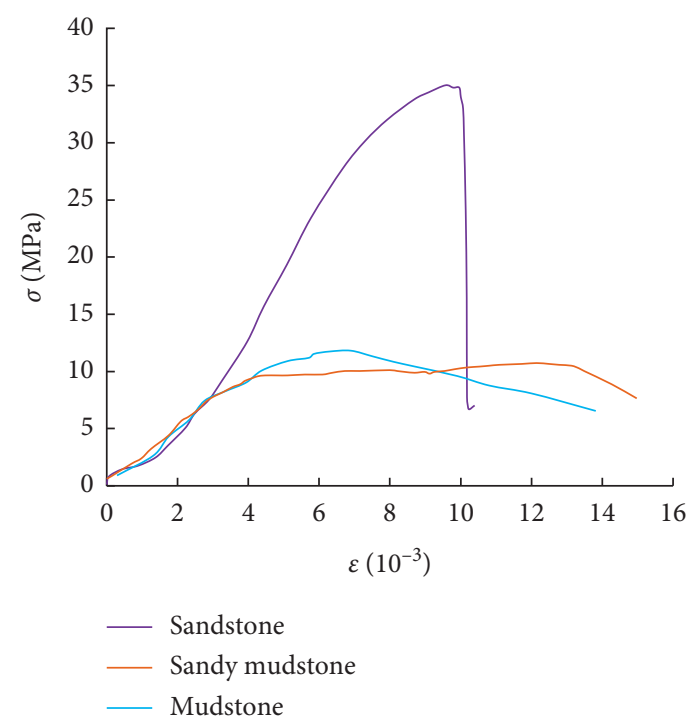

(g)

Figure 4: $\sigma$ - $\varepsilon$ relationship diagram of three rock masses at the same temperature. Stress-strain relationship diagram of three kinds of rock masses (a) at $25^{\circ} \mathrm{C}$, (b) at $30^{\circ} \mathrm{C}$, (c) at $35^{\circ} \mathrm{C}$, (d) at $40^{\circ} \mathrm{C}$, (e) at $45^{\circ} \mathrm{C}$, (f) at $50^{\circ} \mathrm{C}$, and $\left(\mathrm{g}\right.$ ) at $55^{\circ} \mathrm{C}$.

temperature and pressure, cracks will be generated first, and then slip, which will reduce the cementing force. So sandy mudstone and mudstone will have an obvious yield stage. As the temperature rises, the particles of the sandstone slippage will reach a new force balance state for a short time, so a short yield stage appears. Then, the new balance state will be destroyed. The cohesion between the particles and the frictional force is completely lost, brittle failure occurs, and there is no residual stress; however, the structure of sandy mudstone and mudstone changes and some cracks are closed because of the evaporation of the internal water and decomposition of organic matter. Then, new cracks will be generated, causing slow plastic failure.

3.3. The Influence of Temperature on Three Soft Rock Mechanical Parameters. The relationship between the peak stress and elastic modulus of the three soft rocks with temperature is shown in Figure 5.

It can be seen from Figure 5 that

(i) Within the test temperature range, the peak stress and elastic modulus of the three types of soft rocks have been continuously decreased with increasing temperature. Before $40^{\circ} \mathrm{C}$, the peak stress drops significantly; after $40^{\circ} \mathrm{C}$, the downward trend of the peak stress curve decreases.

(ii) The average decreasing rate of peak stress of sandstone is $0.193 \mathrm{MPa} /{ }^{\circ} \mathrm{C}$, followed by sandy mudstone and mudstone, which are $0.124 \mathrm{MPa} /{ }^{\circ} \mathrm{C}$ and $0.051 \mathrm{MPa} /{ }^{\circ} \mathrm{C}$, respectively. (iii) The elastic modulus of sandstone changes most obviously with temperature, with an average decline rate of $0.041 \mathrm{GPa} /{ }^{\circ} \mathrm{C}$, followed by sandy mudstone and mudstone, with decline rates of $0.022 \mathrm{GPa} /{ }^{\circ} \mathrm{C}$ and $0.02 \mathrm{GPa} /{ }^{\circ} \mathrm{C}$, respectively.

\section{Research on the Statistical Constitutive Model of Soft Rock Thermal Damage}

4.1. Establishment of Thermal Damage Constitutive Model. The influence of temperature on the mechanical properties and stability of rock mass cannot be ignored. China's coal mines are confronted with deep mining in the future. For weak rock masses such as sandstone, sandy mudstone, and mudstone with complex and diverse genesis and anisotropy, their compressive strength will change significantly due to temperature. In order to grasp the law of damage caused by temperature rise, according to Weibull distribution [28] and Lemaitre equivalent stress principle [29, 30], three types of soft rock damage constitutive models are constructed as follows:.

$$
\sigma=E \varepsilon\left\{1-\lambda+\lambda \exp \left[-\left(\frac{\varepsilon}{F}\right)^{m}\right]\right\}
$$

where

$$
\begin{aligned}
& m=\frac{\sigma_{D}}{\left[\sigma_{D}+(\lambda-1) E \varepsilon_{D}\right] \ln \left[(1 / \lambda)\left(\left(\sigma_{D} / E \varepsilon_{D}\right)+\lambda-1\right)\right]}, \\
& F=\frac{\varepsilon_{D}}{\left[\sigma_{D} /\left(m\left[\sigma_{D}+(\lambda-1) E \varepsilon_{D}\right]\right)\right]^{1 / m}} .
\end{aligned}
$$

The $m$ and $F$ in formulas (2) and (3) are the characterizing parameters of the internal microdefect distribution 


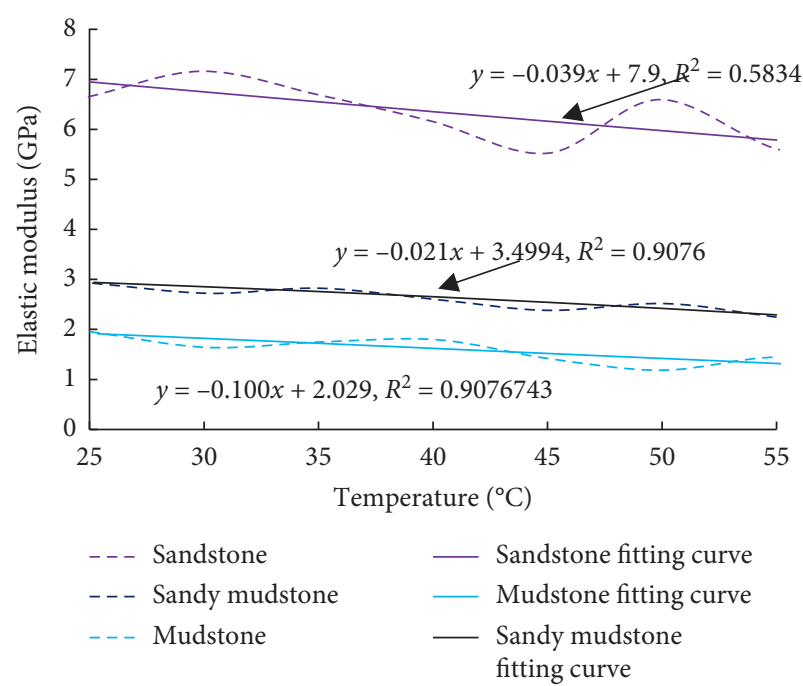

(a)

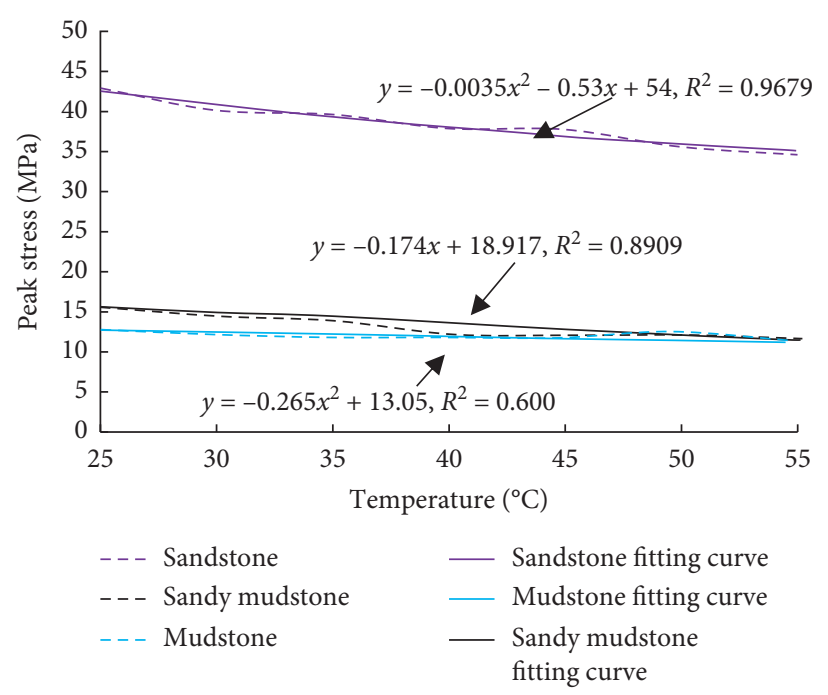

(b)

FIGURE 5: Changes of peak elastic modulus and peak stress of three types of rock masses with temperature under uniaxial compression. (a) The relationship between elastic modulus and temperature. (b) The relationship between peak stress and temperature.

TABLE 1: $m_{0}$ and $F_{0}$ corresponding to different $\lambda$ values.

\begin{tabular}{lcccccc}
\hline Lithology & $\lambda$ & $m_{0}$ & $F_{0}\left(10^{-3}\right)$ & $\sigma(\mathrm{MPa})$ & Average uniaxial compressive strength $(\mathrm{MPa})$ & Selected $\lambda$ value \\
\hline \multirow{3}{*}{ Sandstone } & 1 & 2.717 & 0.0134 & 42.696 & & 44 \\
& 0.95 & 2.759 & 0.0131 & 42.873 & & $\lambda=0.95$ \\
& 0.90 & 2.802 & 0.0127 & 42.843 & & 15 \\
Sandy mudstone & 0.85 & 2.856 & 0.0123 & 42.803 & & $\lambda=0.90$ \\
& 0.95 & 1.803 & 13.634 & 16.7296 & & \\
& 0.90 & 1.892 & 12.433 & 16.7143 & & \\
Mudstone & 0.85 & 1.953 & 11.841 & 16.7179 & & $\lambda=0.95$ \\
& 1 & 2.229 & 0.0145 & 12.8598 & & \\
& 0.95 & 2.265 & 0.0140 & 12.8966 & & \\
& 0.90 & 2.308 & 0.0135 & 12.8525 & & \\
\end{tabular}

characteristics of the material in different states. The distribution characteristic parameters $m$ and $F$ of internal defects must be different with the temperature of the material. The key to establishing the constitutive equation of materials at different temperatures is to find the functional relationship between the parameters $m, F$, and the elastic modulus with temperature. Through the relevant parameters and data of the stress-strain relationship of the standard mudstone specimen at normal temperature $\left(T=25^{\circ} \mathrm{C}\right)$, combined with the statistical relationship (4) of material parameters, elastic modulus, and temperature under uniaxial compression, the following soft rock thermal damage statistical constitutive models under different temperatures can be obtained as shown in formula (5):

$$
\begin{aligned}
E^{\prime} & =A(t) E_{0}, \\
F^{\prime} & =B(t) F_{0} \\
m^{\prime} & =C(t) m_{0} \\
\sigma & =A(t) E_{0} \varepsilon\left\{1-\lambda+\lambda \exp \left[-\left(\frac{\varepsilon}{B(t) F_{0}}\right)^{C(t) m_{0}}\right]\right\},
\end{aligned}
$$

where $\varepsilon$ is the axial strain of soft rock; $\varepsilon_{D}$ is the peak strain of soft rock; $\sigma$ is the axial stress of soft rock; $\sigma_{D}$ is the peak stress of soft rock; $\lambda$ is the damage ratio coefficient of soft rock; $E_{0}$ is the elastic modulus of soft rock material at $25^{\circ} \mathrm{C} ; E^{\prime}$ is the 
TABLE 2: The ratio of $E^{\prime}, F^{\prime}$, and $m^{\prime}$ at test temperature to room temperature.

\begin{tabular}{|c|c|c|c|c|c|c|c|}
\hline Lithology & $T\left({ }^{\circ} \mathrm{C}\right)$ & $E^{\prime}(\mathrm{MPa})$ & $F^{\prime}\left(10^{-3}\right)$ & $m^{\prime}$ & $E^{\prime} / E_{0}$ & $F^{\prime} / F_{0}$ & $m^{\prime} / m_{0}$ \\
\hline \multirow{7}{*}{ Sandstone } & 25 & 2.759 & 0.0131 & 1 & 1 & 1 & 2.759 \\
\hline & 30 & 2.459 & 0.0118 & 1.078 & 0.9017 & 0.891 & 2.459 \\
\hline & 35 & 2.228 & 0.0129 & 1.004 & 0.986 & 0.807 & 2.228 \\
\hline & 40 & 2.467 & 0.0129 & 0.928 & 0.987 & 0.894 & 2.467 \\
\hline & 45 & 3.138 & 0.0132 & 0.832 & 1.011 & 1.137 & 3.138 \\
\hline & 50 & 2.791 & 0.0109 & 0.994 & 0.831 & 1.011 & 2.791 \\
\hline & 55 & 2.618 & 0.0127 & 0.844 & 0.971 & 0.949 & 2.618 \\
\hline \multirow{7}{*}{ Sandy mudstone } & 25 & 2.963 & 12.433 & 1.892 & 1 & 1 & 1 \\
\hline & 30 & 2.848 & 11.128 & 2.098 & 0.961 & 0.895 & 1.109 \\
\hline & 35 & 2.846 & 10.4862 & 2.275 & 0.961 & 0.843 & 1.202 \\
\hline & 40 & 2.662 & 10.552 & 1.706 & 0.898 & 0.849 & 0.902 \\
\hline & 45 & 2.422 & 10.167 & 2.754 & 0.817 & 0.818 & 1.456 \\
\hline & 50 & 2.531 & 6.130 & 2.041 & 0.854 & 0.493 & 1.079 \\
\hline & 55 & 2.334 & 9.626 & 3.236 & 0.788 & 0.774 & 1.710 \\
\hline \multirow{7}{*}{ Mudstone } & 25 & 1990 & 0.014544 & 2.2286 & 1 & 1 & 1 \\
\hline & 30 & 1674 & 0.015639 & 4.171146 & 0.841206 & 1.075289 & 1.871644 \\
\hline & 35 & 1771 & 0.012762 & 3.720534 & 0.88995 & 0.877475 & 1.669449 \\
\hline & 40 & 1824 & 0.013962 & 3.924301 & 0.916583 & 0.959983 & 1.760882 \\
\hline & 45 & 1452 & 0.010854 & 11.19127 & 0.729648 & 0.746287 & 5.021659 \\
\hline & 50 & 1445 & 0.013778 & 4.91244 & 0.726466 & 0.947332 & 2.204272 \\
\hline & 55 & 1480 & 0.007929 & 32.26359 & 0.743719 & 0.545173 & 14.47707 \\
\hline
\end{tabular}

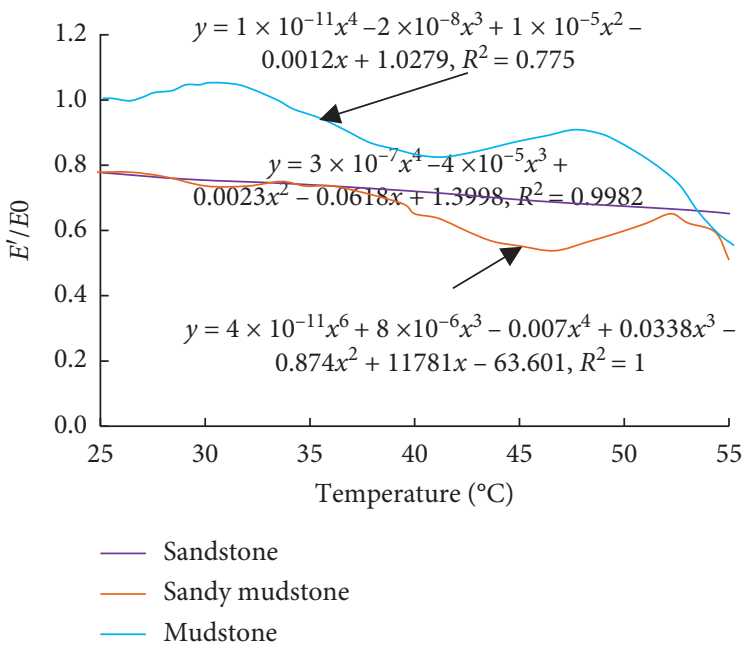

(a)

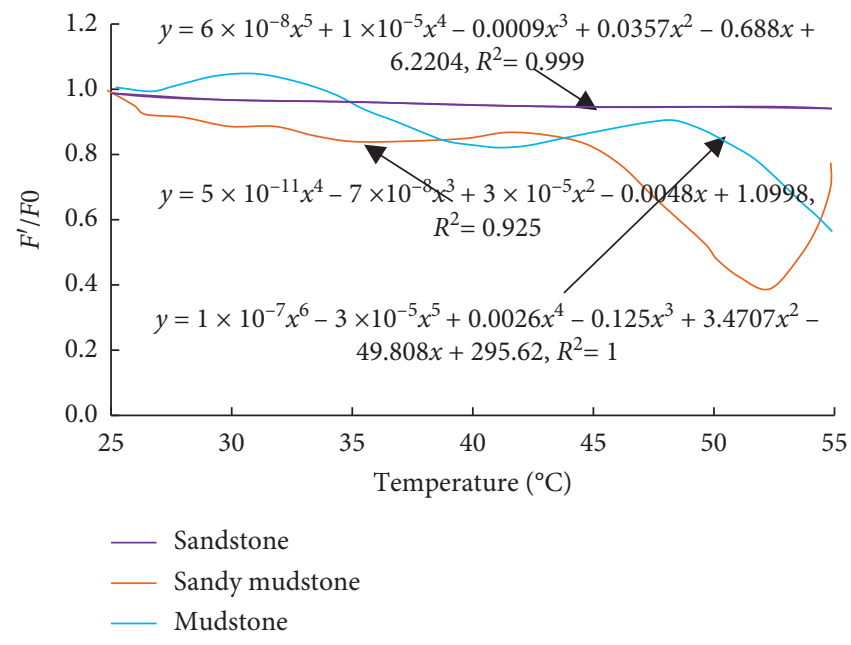

(b)

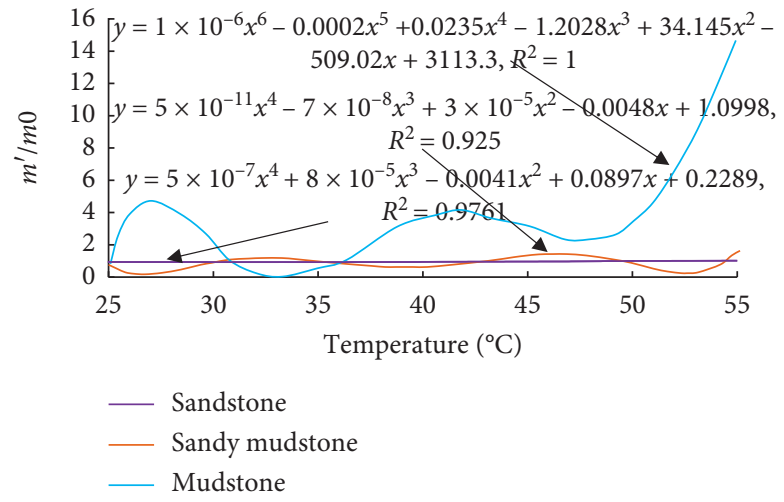

(c)

Figure 6: The curves of (a) $E^{\prime} / E_{0}$, (b) $F^{\prime} / F_{0}$, and (c) $\mathrm{m}^{\prime} / \mathrm{m}_{0}$ with temperature. 
TABLe 3: Values of $A(t), B(t)$, and $C(t)$ at each test temperature.

\begin{tabular}{|c|c|c|c|c|}
\hline Lithology & Temperature $\left({ }^{\circ} \mathrm{C}\right)$ & $A(t)$ & $B(t)$ & $C(t)$ \\
\hline \multirow{7}{*}{ Sandstone } & 25 & 1.0455 & 1.0048 & 0.9361 \\
\hline & 30 & 1.0439 & 1.0483 & 0.6362 \\
\hline & 35 & 1.0308 & 1.0747 & 0.4731 \\
\hline & 40 & 1.0063 & 1.0882 & 0.4071 \\
\hline & 45 & 0.9703 & 1.0930 & 0.3987 \\
\hline & 50 & 0.9229 & 1.0930 & 0.408 \\
\hline & 55 & 0.8640 & 1.0927 & 0.3954 \\
\hline \multirow{7}{*}{ Sandy mudstone } & 25 & 85.846 & -25.510 & 405.378 \\
\hline & 30 & 149.069 & -67.590 & 1001.600 \\
\hline & 35 & 237.841 & -152.820 & 2153.753 \\
\hline & 40 & 355.799 & -309.980 & 4181.300 \\
\hline & 45 & 505.981 & -579.852 & 7508.703 \\
\hline & 50 & 690.449 & -1018.030 & 12674.800 \\
\hline & 55 & 909.466 & -1696.607 & 20353.428 \\
\hline \multirow{7}{*}{ Mudstone } & 25 & 0.998559 & 1.003841 & 0.997476 \\
\hline & 30 & 1.004532 & 1.000368 & 0.980951 \\
\hline & 35 & 1.010092 & 0.997308 & 0.965624 \\
\hline & 40 & 1.015254 & 0.994646 & 0.951448 \\
\hline & 45 & 1.020031 & 0.992369 & 0.938376 \\
\hline & 50 & 1.024438 & 0.990463 & 0.926363 \\
\hline & 55 & 1.028486 & 0.988914 & 0.915361 \\
\hline
\end{tabular}

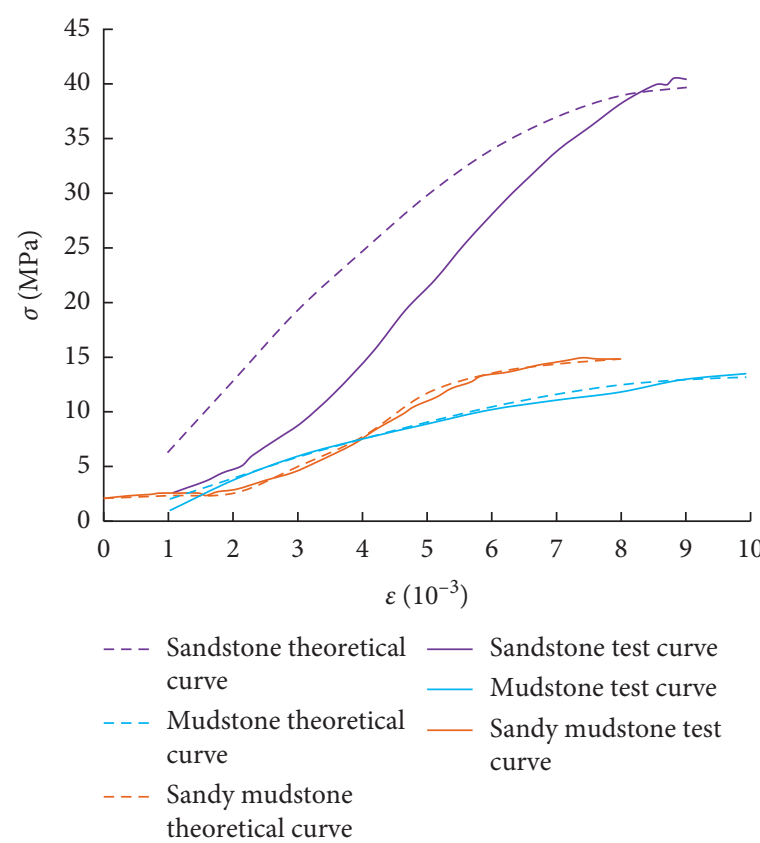

(a)

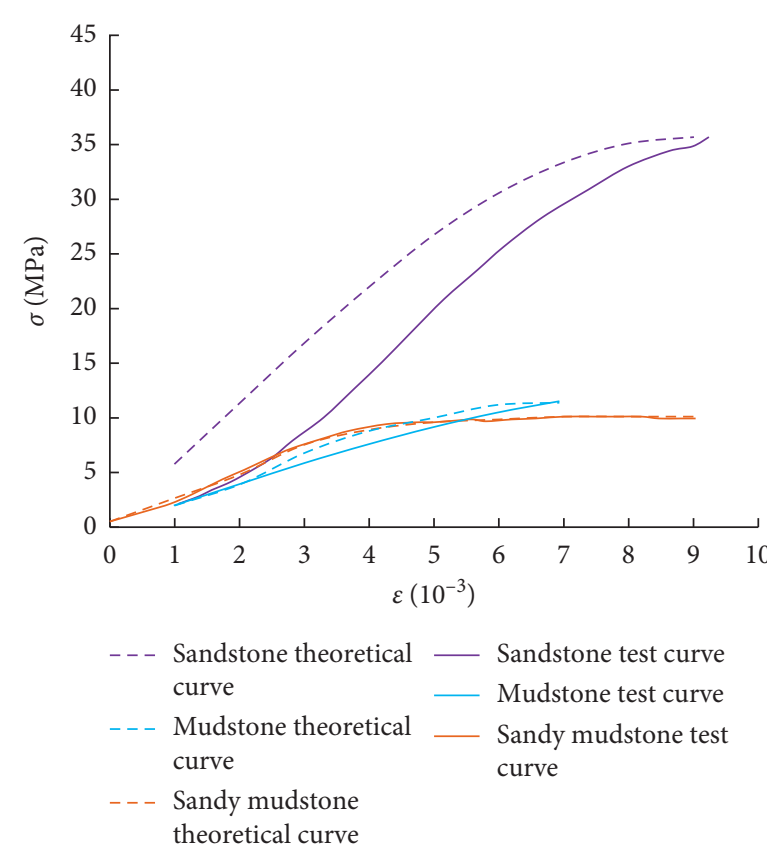

(b)

Figure 7: Comparison of the theoretical curve and the experimental curve before peak: (a) $35^{\circ} \mathrm{C}$ and (b) $55^{\circ} \mathrm{C}$.

corresponding elastic modulus of soft rock at different temperatures; $F_{0}$ and $m_{0}$ are material parameters of soft rock at $25^{\circ} \mathrm{C} ; F^{\prime}$ and $m^{\prime}$ are material parameters corresponding to soft rock at different temperatures; $A(t)$ is the relationship between the elastic modulus and temperature $t$ of soft rock at various temperatures; $B(t)$ is the relationship between parameter $F$ and temperature $t$ at various temperatures of soft rock; and $C(t)$ is the relationship between the parameter $m$ and the temperature $t$ of the soft rock at various temperatures.
By calculating the values of $E_{0}, F_{0}, m_{0}, A(t), B(t)$, and $C(t)$ under the corresponding temperature and substituting them into formula (5), the thermal damage constitutive equation can be obtained.

4.1.1. Determination of $\lambda$ Value. Different damage scale factors $\lambda$ will affect the rationality of establishing the constitutive model. According to the literature [31], 1, 0.95, 0.90, and 0.85 
are selected as the three types of soft rock damage scale factors. Combined with the results of mechanical experiments, the environment at $25^{\circ} \mathrm{C}$ is selected. $E_{0}, \sigma_{D}$, and $\varepsilon_{D}$ of each soft rock in the group and $m_{0}$ and $F_{0}$ under different $\lambda$ values are calculated. According to (1), the theoretical constitutive model of each soft rock under different $\lambda$ values is obtained, and the $\lambda$ value similar to the uniaxial compressive strength of each original rock at $25^{\circ} \mathrm{C}$ is selected as the damage ratio coefficient of each soft rock. The relevant parameters are shown in Table 1.

4.1.2. Calculation of $E^{\prime} / E_{0}, F^{\prime} / F_{0}$, and $m^{\prime} / m_{0}$. According to $E^{\prime}, \sigma_{D}$, and $\varepsilon_{D}$ of each soft rock at different test temperatures, substituting them into formulas (2) and (3), the corresponding $m^{\prime}$ and $F^{\prime}$ can be obtained. Then, $E^{\prime} / E_{0}$, $F^{\prime} / F_{0}$, and $m^{\prime} / m_{0}$ were calculated at each test temperature, as shown in Table 2. Then, fit the three sets of ratios and temperature function curves, as shown in Figure 6.

4.1.3. Calculation of $A(t), B(t)$, and $C(t)$ Values. According to the fitting formula in Figure 6, the values of $A(t), B(t)$, and $C(t)$ at different step temperatures can be obtained. The calculation results are shown in Table 3.

4.2. Verification of the Thermal Damage Constitutive Model. Substituting the values in Tables 1-3 into formula (5), the thermal damage constitutive model of each soft rock at different temperatures can be obtained. In order to test the rationality of the constitutive equation, the theoretical curve and the experimental curve at $35^{\circ} \mathrm{C}$ and $55^{\circ} \mathrm{C}$ were compared. As shown in Figure 7, it can be seen that the theoretical curve of the specimen predicted by the constitutive model and the test curve are in good agreement before the peak, indicating that the proposed statistical constitutive model for soft rock damage before the peak considering the temperature effect is reasonable.

\section{Conclusion}

In this study, the remolded sandstone, sandy mudstone, and mudstone specimens were tested for mechanical properties at different temperatures. The mechanical characteristics of the same soft rock under different temperatures and different soft rocks under the same temperature were analyzed, and the following conclusions were obtained:

(i) Within the test temperature range, the stress-strain curves of the three types of soft rocks at different temperatures are roughly divided into four stages: compaction, elasticity, yield, and failure. The proportion of the deformation in the compaction stage to the total deformation gradually decreases with the increase of temperature. Among them, the deformation of sandstone decreased from $25 \%$ to $20 \%$, deformation of sandy mudstone decreased from $20 \%$ to $12.5 \%$, and deformation of mudstone decreased from $15 \%$ to $14.5 \%$.

(ii) When the temperature is lower than $40^{\circ} \mathrm{C}$, the yield stage of the three types of soft rocks is shorter, and the yield stage becomes more and more obvious when the temperature is higher than $40^{\circ} \mathrm{C}$. After the sandstone reaches the failure stage, the rate of stress decline gradually increases and brittle failure occurs, while the stress of mudstone and sandy mudstone will increase before reaching the ultimate strength. Plastic failure will occur, and there will be greater residual strength.

(iii) When the temperature is lower than $40^{\circ} \mathrm{C}$, the peak stress and elastic modulus of the three types of soft rocks are significantly reduced with increasing temperature; after $40^{\circ} \mathrm{C}$, the downward trend decreases, and the elastic modulus of sandstone decreases at a rate of $0.041 \mathrm{GPa} /{ }^{\circ} \mathrm{C}$. The peak stress decrease rate is $0.193 \mathrm{MPa} /{ }^{\circ} \mathrm{C}$, the sandy mudstone decrease rate is $0.022 \mathrm{GPa} /{ }^{\circ} \mathrm{C}$ and $0.124 \mathrm{MPa} /{ }^{\circ} \mathrm{C}$, and the mudstone decrease rate is $0.020 \mathrm{GPa} /{ }^{\circ} \mathrm{C}$ and $0.051 \mathrm{MPa} /{ }^{\circ} \mathrm{C}$.

(iv) It is verified that the thermal damage constitutive model of sedimentary soft rock established by thermal damage theory and statistical strength theory is reasonable. It can provide a theoretical basis for the analysis of the surrounding rock deformation mechanism of the roadway under the high-temperature environment of the deep well.

\section{Data Availability}

The data used in this paper are available from the corresponding author upon request.

\section{Conflicts of Interest}

The authors declare that they have no conflicts of interest.

\section{Acknowledgments}

This work was supported in part by the Natural Science Foundation of China (NSFC) (51964002, 51474005, and 51974008) and in part by the Research and Development Program of Anhui Province (no. 1804b06020361).

\section{References}

[1] Z. K. Zhang, "Simulation and application of wind temperature at coal mining face in high temperature mine," Science and Technology Innovation, no. 12, pp. 147-148, 2020.

[2] W. H. Cha, X. L. Song, and T. F. Wu, "Experimental study on the mechanical characteristics of coal-measure sandy mudstone under different temperature conditions," Chinese Journal of Rock Mechanics and Engineering, vol. 33, no. 04, pp. 809-816, 2014.

[3] Y. D. Luo, H. N. Wang, and Y. B. Zhang, "Research and application of cooling technology for mine high-temperature tunneling," Nonferrous Metal Science and Engineering, vol. 11, no. 01, pp. 85-91, 2020.

[4] X. W. Liu, Q. S. Liu, C. B. Lu et al., "Research on numerical manifold method of rock mass crack propagation under temperature-stress coupling," Chinese Journal of Rock Mechanics and Engineering, vol. 33, no. 07, pp. 1432-1441, 2014. 
[5] Y. J. He, R. Guo, and X. J. Tian, "Research on deep well thermal damage and its treatment technology," Energy Technology and Management, vol. 44, no. 01, pp. 1-4, 2019.

[6] Y. M. Hu, "Application of mine geothermal and thermal hazard treatment technology," Energy Technology and Management, vol. 43, no. 06, pp. 159-160, 2018.

[7] T. B. Yin, X. B. Li, Z. Q. Yin et al., "Research and comparison of static and dynamic mechanical properties of sandstone after high temperature," Chinese Journal of Rock Mechanics and Engineering, vol. 31, no. 02, pp. 273-279, 2012.

[8] J. Chen, "Research status of deep well thermal damage control and geothermal energy utilization," Shanxi Coking Coal Science and Technology, vol. 43, no. 08, pp. 4-10, 2019.

[9] Q. Ping, M. J. Wu, Y. Pu et al., "Experimental study on dynamic mechanical properties of high temperature sandstone under impact load," Chinese Journal of Rock Mechanics and Engineering, vol. 38, no. 4, pp. 782-792, 2019.

[10] R. R. Zhang, "Experiment and analysis of dynamic mechanics and damage characteristics of deep sandstone after different temperature treatments," Chinese Journal of Rock Mechanics and Engineering, vol. 37, no. S2, pp. 3879-3890, 2018.

[11] P. S. Zhang, C. Y. Zhao, J. Q. Hou et al., "Experimental study on seepage characteristics of red sandstone under temperature-stress-seepage coupling conditions," Chinese Journal of Rock Mechanics and Engineering, vol. 39, no. 10, pp. 19571974, 2020.

[12] G. Wu, D. Y. Wang, S. T. Zhai et al., "Experimental study on the mechanical properties of marble at high temperature," Chinese Journal of Rock Mechanics and Engineering, vol. 31, no. 06, pp. 1237-1244, 2012.

[13] Y. L. Chen and Y. Zhang, "Experimental study on physical and mechanical properties of limestone heat-treated at different temperatures," Chinese Journal of Rock Mechanics and Engineering, vol. 36, no. S2, pp. 3732-3739, 2017.

[14] Q. Ping, H. Sun, C. Zhang, and X. Zhou, "Physics and dynamics characteristics and energy analysis of freeze-thaw limestone," Advances in Civil Engineering, vol. 2020, Article ID 8820172, 12 pages, 2020.

[15] J. Wang, E. B. Li, Y. H. Tan et al., "Comparative experimental study on dynamic mechanical properties of layered salt rock and mudstone interlayer," Chinese Journal of Rock Mechanics and Engineering, vol. 36, no. 12, pp. 3002-3011, 2017.

[16] P. Yuan, N.-N. Wei, Q.-Y. Ma, and J.-C. Chang, "Coupled effect of water temperature and cyclic wetting and drying on dynamic mechanical characteristics of sandstone," Advances in Civil Engineering, vol. 2019, Article ID 8167651, 15 pages, 2019.

[17] R.-r. Zhang and P. Yuan, "Effect of hydrothermal coupling on physical and dynamic mechanical properties of sandstone," Advances in Civil Engineering, vol. 2019, Article ID 7318768, 14 pages, 2019.

[18] B. B. Li, C. H. Ren, K. Yang et al., "Coal and rock damage constitutive model and parameter analysis considering temperature effect," Journal of Safety and Environment, vol. 19, no. 6, pp. 1947-1954, 2019.

[19] L. Chen, X. Mao, S. Yang, C. An, and P. Wu, "Experimental investigation on dynamic fracture mechanism and energy evolution of saturated yellow sandstone under different freeze-thaw temperatures," Advances in Civil Engineering, vol. 2019, Article ID 2375276, 16 pages, 2019.

[20] G. Liu and K. Fan, "Research on overlying strata structure and stress feature aroused by mountainous shallow-buried coal seam mining," Rock Characterisation, Modelling and Engineering Design Methods, vol. 30, no. 04, pp. 583-588, 2013.
[21] G. Wu, N. G. Teng, and Y. Wang, "Study on the physical and mechanical properties of limestone after high temperature," Chinese Journal of Geotechnical Engineering, vol. 33, no. 02, pp. 259-264, 2011.

[22] M. Torabi-Kaveh, M. Heidari, H. Mohseni et al., "Role of petrography in durability of limestone used in construction of persepolis complex subjected to artificial accelerated ageing tests," Environmental Earth Sciences, vol. 78, no. 10, pp. 1-18, 2019.

[23] M. H. Ghobadi and R. Babazadeh, "Experimental studies on the effects of cyclic freezing-thawing, salt crystallization, and thermal shock on the physical and mechanical characteristics of selected sandstones," Rock Mechanics and Rock Engineering, vol. 48, no. 3, pp. 1001-1016, 2014.

[24] W. G. P. Kumari, P. G. Ranjith, M. S. A. Perera et al., "Mechanical behaviour of Australian Strathbogie granite under in-situ stress and temperature conditions: an application to geothermal energy extraction," Geothermics, vol. 65, pp. 44-59, 2017.

[25] Y. Wang, H. Wang, and X. Shi, "Creep investigation on shalelike material with preexisting fissure under coupling temperatures and confining pressures," Advances in Civil Engineering, vol. 2019, Article ID 7861305, 10 pages, 2019.

[26] W. H. Zha, X. L. Song, T. F. Wu et al., "Experimental study on the influence of temperature on the mechanical characteristics of coal measure mudstone," Rock and Soil Mechanics, vol. 35, no. 5, pp. 1334-1339, 2014.

[27] W. H. Zha and X. L. Song, "The influence of temperature changes on the mechanical properties of coal-measure sandy mudstone under triaxial compression," Journal of Safety and Environment, vol. 14, no. 6, pp. 47-51, 2014.

[28] B. Pan Bin, P. J. Lou, C. J. Li et al., "Analysis on the damage characteristics of brittle rock under the action of staged cyclic loading and unloading," Coal Mine Safety, vol. 50, no. 3, pp. 203-207, 2019.

[29] M. Tavoosi, M. Sharifian, and M. Sharifian, "Updating stress and the related elastoplastic parameters for Lemaitre damage model," Iranian Journal of Science and Technology, Transactions of Mechanical Engineering, vol. 44, no. 3, pp. 647-659, 2020.

[30] D. Skibicki and B. Ligaj, "Application of continuum damage mechanics model in terms of fatigue life assessment for low cycle and quasi static loadings," Materialwissenschaft und Werkstofftechnik, vol. 49, no. 8, pp. 1026-1039, 2018.

[31] W. G. Cao, H. Zhao, L. Zhang et al., "Rock damage statistical softening constitutive model considering the influence of damage threshold and its parameter determination method," Chinese Journal of Rock Mechanics and Engineering, no. 6, pp. 1148-1154, 2008. 